\title{
Silicalite-1 formation in acidic medium: synthesis conditions and physicochemical properties
}

\author{
Xiaobo Yang, ${ }^{\text {a, }}$ Eddy Dib, ${ }^{\mathrm{b}}$ Qiaolin Lang, ${ }^{\mathrm{a}}$ Hailing Guo, ${ }^{\mathrm{c}}$ Guangying Fu, ${ }^{\mathrm{a}}$ Juan Wang, ${ }^{\mathrm{a}}$ Qisong Yi, \\ Haonuan Zhao, ${ }^{\mathrm{a}, \mathrm{b}}$ Valentin Valtcheva, ${ }^{\mathrm{a}, \mathrm{,*}}$ \\ a The ZeoMat Group, Qingdao Institute of Bioenergy and Bioprocess Technology, CAS, Laoshan \\ District, CN-266101 Qingdao, China. \\ ${ }^{\mathrm{b}}$ Normandie University, ENSICAEN, UNICAEN, CNRS, Laboratoire Catalyse et Spectrochimie, F- \\ 14050 Caen, France. \\ ${ }^{\mathrm{c}}$ State Key Laboratory of Heavy Oil Processing, College of Chemical Engineering, China University \\ of Petroleum (East China), CN-266580, Qingdao, China \\ * Corresponding author. \\ ** Corresponding author. \\ E-mail address: valentin.valtchev@ensicaen.fr (V.Valtchev), yangxb@qibebt.ac.cn (X. Yang).
}

\begin{abstract}
Zeolites are the catalytic materials that are widly applied in the processing of conventional and renewable fuels and chemicals. The present study provides a comprehensive analysis of the factors controlling the acidic medium synthesis of high silica silicalite- 1 zeolite. The effect of various silica sources (TEOS, fumed and colloidal silica) and alkali metal cations (Na and K) on the silicalite-1 formation is studied. The efficiency of different types of seeds (micron-sized, nanosized, and silicalite-1 amorphous colloidal precursor) on the silicalite-1 crystal growth kinetics and crystal size formed under acidic conditions is also investigated. Further, the zeolite crystallization kinetics under acidic, neutral, and basic conditions is compared. The obtained highly crystalline samples are used to compare the physicochemical properties of zeolites synthesized in acidic, neutral, and basic medium. Thus, the crystallinity, thermal stability, and local order in silicalite-1 samples synthesized in the (212) $\mathrm{pH}$ range are evaluated.
\end{abstract}

Keywords: Zeolite crystallization in acidic medium; defect-free silicalite-1; crystal size control; seeding with zeolitic embyos; structure integrity and thermal stability.

\section{Introduction}

The synthetic aluminosilicate zeolites are technical materials having wide applications as catalysts and adsorbents in crude oil refineries and petrochemical productions, owing to their unique crystalline framework structures with defined micropore/cage systems and adjustable framework compositions [1-3]. In recent years their uses have been extended to the processing of coal and natural gas derived methanol, environmental protection industries, and advanced applications in optics, electronics, and medicine $[1,4,5]$. However, the applications in renewable energy, e.g., catalytic conversion of biomass into fuels and chemicals, raise new requirements that zeolites should possess high structural integrity and less defects so that they survive harsh aqueous conditions [6]. Concequently, the synthetic chemistry of zeolite should be reviewed and improved. 
Since the commercialization in the late 1950's, several methods for zeolite synthesis have been developed that lead to products with various structural, compositional, and surface-chemical properties [7, 8]. Represented by NaA (framework topology code LTA) and NaX (FAU), highalumina zeolites with polarized and hydrophilic surfaces crystallize in strongly basic aqueous solutions of alkaline hydroxides at $\mathrm{pH} 12-14$ [9]. High-silica and pure-silica polymorphs of zeolites with hydrophobic surfaces, such as ZSM-5 and silicalite-1 (both MFI), crystallize in weakly basic media using tetraalkylammonium cations instead of alkaline metal ions as structure-directing agents [10]. The $\mathrm{pH}$ range of the initial hydrogels is reduced to $8-12$. In "fluoride route", the hydroxide anion, used in the conventional zeolite synthesis as the mineralizer, is replaced by fluoride anions, and the $\mathrm{pH}$ can be further lowered to the near-neutral range of $6-8$. Under such conditions, usually bigger crystals having "perfect" lattices with few point-defects are formed [11, 12].

The crystallization of zeolites in the above chemical systems generally follows a common paradigm, as illustrated by Davis et al. with MFI type zeolite as a representative example $[13,14]$. In this paradigm, zeolite formation is initiated by the reaction between the structure-directing agent (SDA), usually a cation or positively charged molecule, and silicate anions in the zone of supersaturation. Silicate anions approach an SDA cation, substitute water molecules in the cation hydrate shield, and become hydrolyzed/condensed with each other. Thus, an organized structure of SDA/oligomerized silicates is formed. These structured composites assemble themselves further to form nuclei, which after reaching a critical size, kick off the process of crystal growth. The interface of gel particles to the solution phase is considered the place where the fast exchange between liquid and solid phase facilitates the nuclei formation [15].

The concept of crystallizing zeolites in acidic media is an extension of the above chemistry. In acidic systems, the same paradigm holds, as long as the solution $\mathrm{pH}$ stays above the isoelectric point of the solute silicate ions. Over the isoelectric point, the silica species remain negatively charged and are attracted by the SDA cation. A recent work pointed out the possibility to extend the crystallization filed of zeolites, without however to establish the limits of acid medium zeolite formation [16]. Also, the properties of materials synthesized under acidic conditions needs to be carefully studied in order to evaluate their practical value. Besides, a relevant application is the isomorphous substitution of those transition metals in zeolite frameworks that would otherwise precipitate in basic or neutral media.

The development of zeolite synthesis in the acidic medium is important because many potential adsorption and catalysis applications require zeolites with pre-determined size and surface chemistry. Hence, a comprehensive analysis of the factors controlling zeolite formation in an acidic medium is the objective of the present study. Silicalite- 1 is used as a model material, and the impact of slow nucleation/growth on zeolite crystals size is addressed; means to accelerate zeolite formations and to control the crystal sizes are illustrated. Also, the effect of various silica sources on zeolite formation in an acidic medium is investigated. The physicochemical properties of acidic medium yielded zeolite samples are thoroughly studied and compared with those of their neutral and basic medium synthesized counterparts.

\section{Experimental}

\subsection{Synthesis}

Chemical reagents used for the synthesis of silicalite-1 in acidic medium were tetra-n-propylammonium bromide (TPABr, Sigma-Alrich, 98\%), tetraethyl-orthosilicate (TEOS, Sigma-Aldrich, a.p.), colloidal silica (Silica sol 30, Macklin, 29-31\% aq., $\mathrm{SiO}_{2} / \mathrm{Na}_{2} \mathrm{O} \sim 100$, $\mathrm{pH}$ 9-10.5, particle size 7$10 \mathrm{~nm}$ ), colloidal silica (Ludox AS-40, Sigma-Aldrich, $40 \%$ aq., $\mathrm{SiO}_{2} / \mathrm{Na}_{2} \mathrm{O} \sim 200$, pH 9-9.5, particle sizes 20-24 nm), fumed silica (Macklin. 98\%), ammonium fluoride (Aladin, 98\%), and hydrofluoric acid (Aladin, 40\%). 
Table S1 in the Supplementary Information provides the list of silicalite-1 samples that are prepared and discussed in the present paper. They have been synthesized in acidic, neutral, and basic media, using various silica sources, in the absence or presence of different types of seeds.

The hydrothermal syntheses in acidic media were carried out according to the following procedure: $\mathrm{TPABr}, \mathrm{NH}_{4} \mathrm{~F}$, and $\mathrm{HF}$ were dissolved in a proper amount of water. Then a silica precursor was added to the solution and stirred at room temperature for 4-20 hours (20 hours when TEOS was used as the silica source, and 8 hours for fumed silica, 4 hours for colloidal silica). The resultant hydrogels had molar compositions $1 \mathrm{SiO}_{2}$ : (0.3-0.5) TPABr: (0.1-0.2) $\mathrm{NH}_{4} \mathrm{~F}$ : (0.3-0.4) HF: (30-40) $\mathrm{H}_{2} \mathrm{O}$. When required, seeds were added at this stage, and the gels were further stirred for $10 \mathrm{~min}$. The seeding amount was 1-3 wt.\% of silica content in the gel. The additional amounts of water with seeds was 0.61.8 wt.\% respecting the water content in the initial gel. Eventually additional TPAOH were also mixed in the gel when the clear amorphous gel or the unprocessd nano-crystals in the mother liquor were used as the seed. The additional amount of $\mathrm{TPA}^{+}$was 1-3 wt.\%. Corresponding $\mathrm{pH}$ changes were recorded. A portion of each precursor gel was centrifuged at $30,000 \mathrm{rpm}$ for $60 \mathrm{~min}$ at $25^{\circ} \mathrm{C}$, and $\mathrm{pH}$ values of the liquid supernatants were measured. Crystallizations of the gels were performed in Teflon-lined autoclaves. The gels were heated statically at $160^{\circ} \mathrm{C}$ for 5 to 30 days until a clear separation of solid sediments, and translucent mother-liquors could be observed. This time point was regarded as the end of crystal growth. Then the solids were centrifuged, thoroughly washed, and dried at $80^{\circ} \mathrm{C}$ in air.

Seeds were prepared from a hydrogel of the composition $1 \mathrm{SiO}_{2}: 0.36 \mathrm{TPAOH}: 20 \mathrm{H}_{2} \mathrm{O}$. $1 \mathrm{M}$ TPAOH solution and TEOS of appropriate amounts were mixed and stirred at room temperature for 24 hours. The resultant gel is a clear fluid. Hydrothermally treated at $90^{\circ} \mathrm{C}$ for 24 hours, a colloid with suspending nano-zeolite spherical particles of a mean diameter of $90 \mathrm{~nm}$ was obtained. Both the clear precursor gel and the colloidal nano-zeolites were employed as seeds.

Furthermore, three reference samples of silicalite-1 were synthesized according to following the recipes:

Ref\#B1 was prepared in a basic medium using the recipe $1 \mathrm{SiO}_{2}: 0.12 \mathrm{TPAOH}: 60 \mathrm{H}_{2} \mathrm{O}$ at initial gel $\mathrm{pH}=12.6$, with TEOS as the silica source, and crystallized at $160^{\circ} \mathrm{C}$ in 24 hours.

Ref\#N1 and Ref\#N2 were prepared in a neutral medium following the recipe $1 \mathrm{SiO}_{2}: 0.3 \mathrm{TPABr}: 0.5$ $\mathrm{NH}_{4} \mathrm{~F}: 40 \mathrm{H}_{2} \mathrm{O}$ (gel pH =7.0), with Ludox AS40 as the silica source. Ref\#N1 was crystallized in the absence of any seed. 2 wt.\% colloidal nano-crystal seeds (gel $\mathrm{pH}=7.3$ ) in respect to the silica content in the gel were added to Ref\#N2. Ref\#N1 was crystallized at $160^{\circ} \mathrm{C}$ in 7 days. Ref\#N2 was crystallized at $160^{\circ} \mathrm{C}$ in 3 days. The reference samples were purified as described above.

\subsection{Characterization}

Powder X-ray diffraction was performed on a Rigaku SmartLab 9KW diffractometer using $\mathrm{Cu} \mathrm{K} \alpha$ radiation at $40 \mathrm{kV}$ and $150 \mathrm{~mA}$. 1D detector was used to collect diffraction data in a continuous scan mode in theta-theta geometry. Zeolite samples are pressed on glass plate sample holders without grinding so that preferred orientations of larger crystals became apparent. XRD patterns at higher temperatures (HT) up to $1500^{\circ} \mathrm{C}$ of selected samples were recorded using a Rigaku multipurpose HT chamber with Be windows. The sample was exposed to ambient air with $70 \%$ humidity and heated at a rate of $5^{\circ} \mathrm{C} / \mathrm{min}$ at $50^{\circ} \mathrm{C}$ steps. At each step, the temperature was held for $5 \mathrm{~min}$ for XRD recording. The sample holder for this purpose was a Pt plate.

SEM pictures of powder samples were taken on JEOL JSM 7900F Scanning Electron Microscope equipped with a field emission gun operating at $1-2 \mathrm{kV}$. The samples were dusted on carbon sheets and inspected without coating.

FTIR spectra were recorded upon $\mathrm{KBr}$ pellets using Brucker Vertex 70V Spectrometer at a spectral resolution of $4 \mathrm{~cm}^{-1}$. The equipment, including the sample chamber, was evacuated to below $1 \mathrm{hPa}$. The in situ FTIR studies were performed on self-sustaining pellets of the density $15 \mathrm{mg} / \mathrm{cm}^{2}$, which 
are enclosed in a gas-tight and heatable cell with $\mathrm{CaF}_{2}$ windows. Spectra were recorded in $30 \mathrm{ml} / \mathrm{min}$ flowing Ar after dehydrations at $25,125,200,350$, and $600^{\circ} \mathrm{C}$ for $30 \mathrm{~min}$, respectively.

TG/DTA analysis was performed using Rigaku TG-DTA8122 microbalance upon ca. $10 \mathrm{mg}$ zeolite powder against $\alpha-\mathrm{Al}_{2} \mathrm{O}_{3}$, in $50 \mathrm{ml} / \mathrm{min}$ reconstituted $\left(80 \% \mathrm{~N}_{2}+20 \% \mathrm{O}_{2}\right)$ airflow at a heating rate of $10^{\circ} \mathrm{C} / \mathrm{min}$.

${ }^{29} \mathrm{Si}\left\{{ }^{1} \mathrm{H}\right\}$ and ${ }^{29} \mathrm{Si}\left\{{ }^{19} \mathrm{~F}\right\}$ cross-polarization (CP) magic-angle spinning (MAS) NMR spectra were acquired at $99.3 \mathrm{MHz}$ on a Bruker Avance III-HD 500 (11.7 T), using 4.0-mm outer diameter probe spun at $12 \mathrm{kHz}$. A recycle delay of $2 \mathrm{~s}$ and a contact time of $7.5 \mathrm{~ms}$ were used. ${ }^{19} \mathrm{~F}$ MAS NMR spectra were acquired using Hahn echo at $470.6 \mathrm{MHz}$ on a Bruker Avance III-HD 500 (11.7 T), using 4.0-mm outer diameter probe spun at $12 \mathrm{kHz}$. A recycle delay of $5 \mathrm{~s}$ and a nutation radiofrequency power of $67.6 \mathrm{kHz}$ were used. The fitting of the NMR spectra is done using Dmfit software [17].

\section{Results and Discussions}

\subsection{Synthesis of silicalite-1 in acidic medium}

The solution with the molar composition $0.36 \mathrm{TPABr}: 0.17 \mathrm{NH}_{4} \mathrm{~F}$ : $0.36 \mathrm{HF}$ : $40 \mathrm{H}_{2} \mathrm{O}$ has a pH value of 4.29 at room temperature. One molar equivalent of a silica precursor has been added to this solution and stirred until the mixture transforms into a homogeneous hydrogel. The aqueous phase of the gels has a $\mathrm{pH}$ in the range of 2.4-2.9 depending on the silica precursor type (Table 1). The variation of $\mathrm{pH}$ depends on the dissolved portion of silica, which varies with different precursors.

Tetraethyl-orthosilicate (TEOS) is a commonly used silica source in zeolite synthesis. Upon hydrolysis, in basic medium, TEOS is converted into homogeneous small silica hydrogel particles with a narrow particle sizes distribution. Such a system also includes low-weight silica species [1820]. Fumed silica used as a zeolite precursor source provides a fairly different hydrogel system. Larger silica gel particles with broad particle size distribution, as well as complex oligomeric silicate solutes, co-exist. Between these two extreme examples, two different types of colloidal silica have been chosen for comparative tests, i.e., silica sol of 30 wt.\% (Macklin Silica sol 30, $\mathrm{SiO}_{2} / \mathrm{Na}_{2} \mathrm{O} \sim 100$ ), and a 40 wt.\% silica sol (Ludox $\mathrm{AS} 40, \mathrm{SiO}_{2} / \mathrm{Na}_{2} \mathrm{O} \sim 200$ ). The experimental parameters and characteristics of hydrogels prepared out of these silica sources, along with some remarks on the obtained hydrothermal products, are summarized in Table 1. Except for TEOS the acidic hydrogels made of all other 3 silica sources have crystallized into silicalite-1 within the time span of experiments.

Table 1. Gel preparation and synthesis of silicalite- 1 from the system $1 \mathrm{SiO}_{2}$ : $0.36 \mathrm{TPABr}: 0.17$ $\mathrm{NH}_{4} \mathrm{~F}$ : $0.36 \mathrm{HF}: 40 \mathrm{H}_{2} \mathrm{O}$ at temperature $160^{\circ} \mathrm{C}$ using various silica sources

\begin{tabular}{lllllll}
\hline$\#$ & Si Source & \multicolumn{2}{l}{ Gel preparation } & \multicolumn{2}{l}{ Hydrothermal synthesis } \\
\cline { 3 - 7 } & & RT stir (h) & $\begin{array}{l}\text { pH of the gel } \\
\text { liquid phase }\end{array}$ & $\begin{array}{l}\text { Time } \\
\text { (day) }\end{array}$ & $\begin{array}{l}\text { Crystal } \\
\text { lengths }(\mu \mathrm{m})\end{array}$ & Yield* \\
\hline A1 & TEOS & 20 & 2.44 & 30 & - & Amorphous \\
A2 & Fumed silica & 8 & 2.82 & 30 & $500-800 / 100$ & $80 \%$ \\
A3 & Silica sol 30 & 4 & 2.90 & 22 & $300-500 / 50$ & $85 \%$ \\
A4 & Ludox AS40 & 4 & 2.81 & 15 & 200 & $85 \%$ \\
\hline
\end{tabular}

\footnotetext{
* The yield is calculated on the silica basis in the initial gel.
} 
The crystallization of silicalite- 1 under acidic conditions is relatively long. It takes 15 days for the colloidal silica Ludox AS40 to convert into silicalite-1; 22 days for Silica sol 30; 30 days for fumed silica. Noteworthy, the acidic hydrogel made of TEOS remains a jelly within 30 days. It becomes a solid semi-transparent gel, where no distinct liquid phase is present, which substantially slowed the crystal growth kinetics. The XRD patterns of silicalite-1 out of Ludox AS40, Silica sol 30, and fumed silica are shown in Figure S1. They agree with the MFI framework type in the orthorhombic symmetry and show significant and abnormal amplification of (200) peak, which indicates a preferred orientation of large crystals. SEM inspection confirms the large sizes of obtained crystals (Figure 1). The 15-day crystals out of Ludox AS40 are prismatic with obelisk-like tips on both ends. They have average dimensions of $30 \times 30 \times 200 \mu \mathrm{m}$ with a narrow size distribution. Two populations of crystals were observed in the product issued from Silica sol 30. The great majority of the crystals were $300-$ $500 \mu \mathrm{m}$ large. A population of smaller $(50-100 \mu \mathrm{m})$ crystals was detected as well. Many of the smaller crystals are intergrown. The crystals obtained within 30 days using fumed silica as the silica source also show bi-modal size distribution, too. The bigger ones exhibit a length of $500-800 \mu \mathrm{m}$, and the smaller intergrown ones are $100 \mu \mathrm{m}$ long. We attribute the presence of two populations of crystals to the heterogeneities of the gels made of the respective silica sources. In contrast with these silica sources, hydrolyzed TEOS results in a homogenous hydrogel with well distinct silica particles, respectively well distinct surfaces, where the slowest nucleation most probably is taking place [15].

The slow growth and formation of big crystals is frequently observed in fluoride medium. In aqueous solutions, monomeric hexafluoro-silicate has high solubility, and thus, reaching a supersaturation state is a long process. Consequently, the number of zeolite nuclei in the system is limited. The growth of the nuclei to crystals, i.e., depositions and reactions of hexafluoro-silicate anions on the growing surfaces, is also a slow reaction [21]. The sample Ref\#N1 has been crystallized in the fluoridecontaining neutral medium (initial gel $\mathrm{pH}=7.0$ ) at $160^{\circ} \mathrm{C}$. It takes 7 days for the completion of crystallization. The crystals exhibit a coffin shape, which is often seen for MFI-type zeolites. Most crystals have lengths around $50 \mu \mathrm{m}$, with only a few exceptions grown up to ca.100 $\mu \mathrm{m}$ long (Figure 1). Shifting the $\mathrm{pH}$ to acidic accentuates the slow crystal growth and further limits the nucleation rate. Few viable nuclei are spontaneously formed. Consequently, giant crystals are obtained in extended durations through slow development.
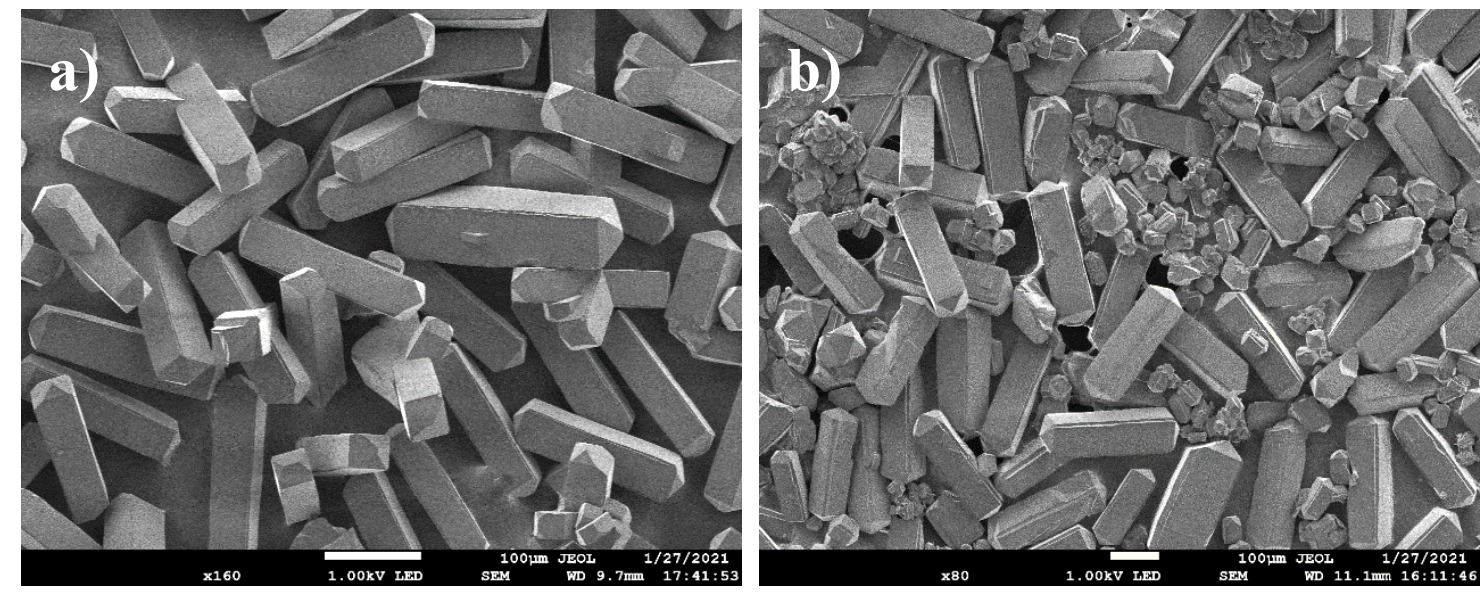

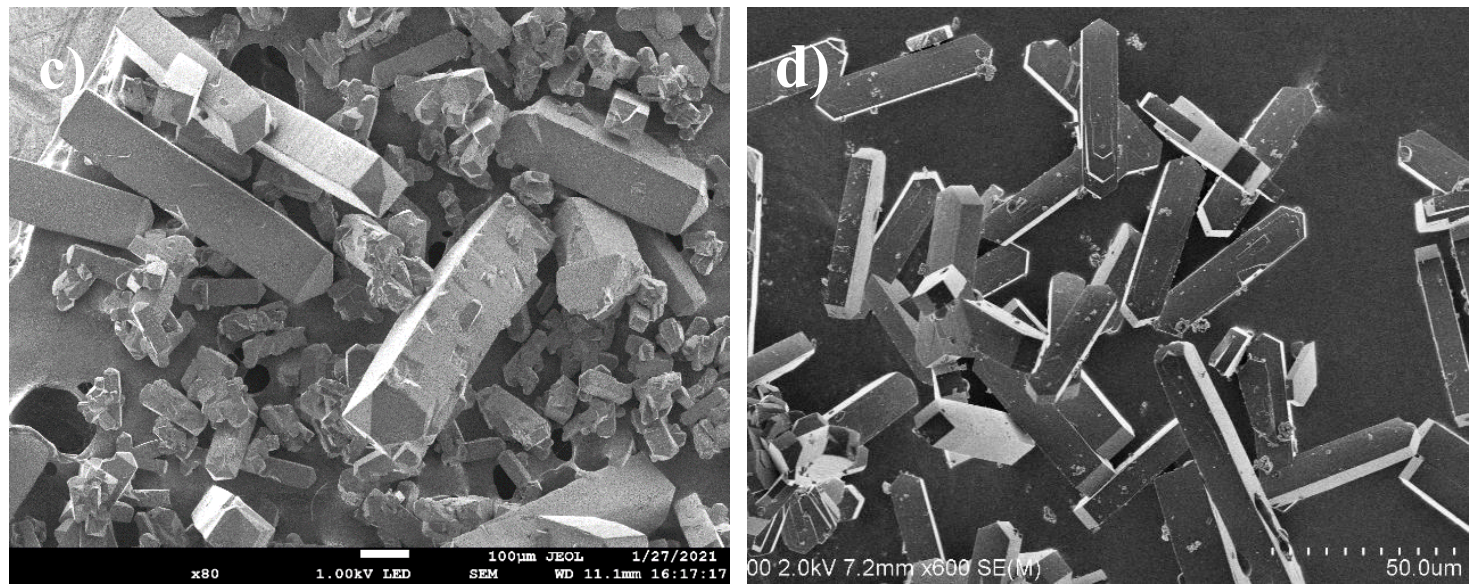

Figure 1. SEM of the products out of hydrogels with the composition $1 \mathrm{SiO}_{2}$ : $0.30 \mathrm{TPABr}: 0.19$ $\mathrm{NH}_{4} \mathrm{~F}$ : $0.36 \mathrm{HF}: 40 \mathrm{H}_{2} \mathrm{O}$ prepared using various silica sources: a) Ludox AS-40; b) Silica sol 30; c) Fumed silica; and d) the reference sample Ref\#N1 crystallized out of Ludox AS40 in the neutral medium.

FTIR has been performed on the liquid phases and the gel particles, respectively, to confirm the place where the initial nucleation occurs (Figure 2). For this purpose, the aged gels have been centrifuged at $25^{\circ} \mathrm{C}$ and $30000 \mathrm{rpm}$ for 1 hour. The supernatant liquids and solids have been separated and freezedried, pressed in $\mathrm{KBr}$ pellets, and subjected to IR measurements. In the spectra of the liquid phase, two absorption bands, in addition to the sharp peaks of TPABr, are attributed to silica phases: the one at $475 \mathrm{~cm}^{-1}$ belongs to the symmetric bending vibration $\delta(\mathrm{O}-\mathrm{Si}-\mathrm{O})$, the band at $725 \mathrm{~cm}^{-1}$ belongs to symmetric bending vibration $\delta$ ( $\mathrm{Si}-\mathrm{O}-\mathrm{Si})[22,23]$. Both bands are sharp because the solute silicate species have narrowly distributed mol masses, therefore simple and uniform structures. In the pseudolattice vibrational region of 500-800 $\mathrm{cm}^{-1}$ there are no distinguishable signals that can be attributed to zeolitic framework units $[24,25]$. These data suggest that the solution contains only low-weight silica species. In the spectra of gel particles, $\delta(\mathrm{O}-\mathrm{Si}-\mathrm{O})$ is broader. The strong $v_{\text {asymmetric }}(\mathrm{Si}-\mathrm{O}-\mathrm{Si})$ at $1100-$ $1200 \mathrm{~cm}^{-1}$, as well as the weaker $\delta$ (Si-O-Si) at $700-800 \mathrm{~cm}^{-1}$, appear as doublets. A band at $550 \mathrm{~cm}^{-1}$, which is weak for the gels made of Silica sol 30 and Ludox AS40, and is more significant for the gels of TEOS and fumed silica, is substantial. It is believed that this band is indicative of MFI zeolite structure and has been attributed tentatively to double 5-rings, but may also belong to other types of pseudo-lattice subunits $[14,25,26]$. This kind of IR-detectible structural unit exists on the gel particles of all four Si sources. However, only the one with Ludox AS40 grows into uniform crystals within 15 days, even though it has the lowest optical density among the IR spectra. The band is most intensive in the TEOS-containing system, but no crystal has been obtained in 30 days. It seems that the moieties with the structural units are not big enough to grow as nuclei. In the other two gels, bimodal products grow in 22 and 30 days, respectively. The band at $970 \mathrm{~cm}^{-1}$ in spectra of the gel solids may be attributed to the asymmetric stretching vibrations of -Si-F bonds capping the silica gel particles [27-29]. This band also presents in the spectra of silicalite-1 crystals synthesized in fluoride media, but are absent for silicalite-1 obtained at the conventional basic conditions (Figure S2b). In the crystalline products $\mathrm{F}^{-}$ions assume disordered sites in the $\left[4^{1} 5^{2} 6^{2}\right]$ cage, bonding with $\mathrm{Si}$ atoms in the vicinity (see NMR characterization in below section). 


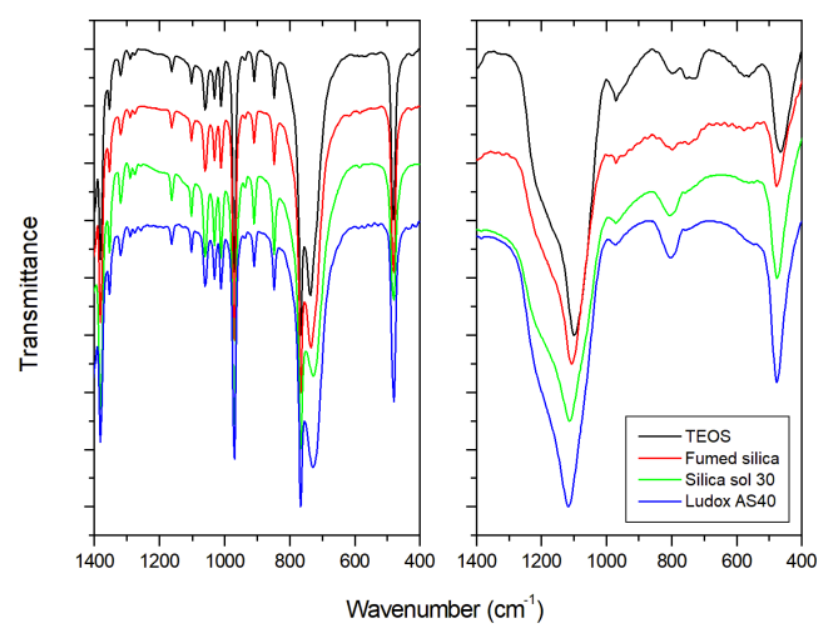

Figure 2. FTIR spectra of the centrifuged supernatant (left) and sediment (right) phases of the acidic gels that are prepared with different silica sources.

\subsection{Impact of $\mathrm{Na}$ and $\mathrm{K}$ ions on the silicalite-1 formation}

The study on the roles of alkali metal cations in zeolite synthesis respecting structure and morphology controls can be dated back to the early works of Barrer on Al-rich materials [30, 31], and extends to high-silica systems and fluoride-containing systems [32-34]. The impact of alkali metals in silicalite-1 formation under acidic conditions was studied in a series of experiments with $\mathrm{NaCl}$ or $\mathrm{KCl}$ added to the gels.

An initial gel has been prepared using Ludox AS40 as the silica source. It has the composition $1 \mathrm{SiO}_{2}$ : $0.50 \mathrm{TPABr}: 0.16 \mathrm{NH}_{4} \mathrm{~F}: 0.37 \mathrm{HF}: 30 \mathrm{H}_{2} \mathrm{O}$. The $\mathrm{pH}$ value of the solution phase of the stirred gel is 3.06. In 15 days at $160^{\circ} \mathrm{C}$ it grows to silicalite- 1 crystals of $200 \mu \mathrm{m}$ in length. Adding $0.1,0.2$ and 0.5 molar equivalents $\mathrm{NaCl}$ and $\mathrm{KCl}$ into this gel, the gels' $\mathrm{pH}$ values decrease slightly with increasing amounts of the alkaline ions, i.e., 2.45, 2.04, 2.02 with increasing $\mathrm{NaCl}$, and 3.04, 2.75, 2.77 with increasing $\mathrm{KCl}$. Both $\mathrm{NaCl}$ and $\mathrm{KCl}$ in amounts of 0.1 and 0.2 (ratios to $\mathrm{SiO}_{2}$ ) do not affect the crystallization rate significantly. The systems still need 15 days to complete the crystallization. The crystals exhibit the characteristic coffin shape of MFI-type zeolite. It should be noted that the crystal thicknesses vary within the batch. Furthermore, the crystal size has changed substantially in the presence of different amounts of $\mathrm{NaCl}$ and $\mathrm{KCl}$. The lengths have been reduced to 50-80 $\mu \mathrm{m}$ at 0.1 $\mathrm{NaCl}$, and further to $15-20 \mu \mathrm{m}$ at $0.2 \mathrm{NaCl}$ (Figure 3). In both cases, intergrows of crystals are frequent. With $\mathrm{KCl}$ the crystal shapes are similar, but the number of intergrows is limited. The crystal lengths are $50-80 \mu \mathrm{m}$ at $0.1 \mathrm{KCl}$ and $40-50 \mu \mathrm{m}$ at $0.2 \mathrm{KCl}$. These results show that small amounts of $\mathrm{NaCl}$ and $\mathrm{KCl}$ promote the silicalite- 1 nucleation and generate larger numbers of crystals in the systems, thus decrease the crystal size. However, at 0.5 molar equivalents of $\mathrm{NaCl}$ and $\mathrm{KCl}$, the nucleation process has been disturbed, and no crystalline product was obtained after 30 days of crystallization. 

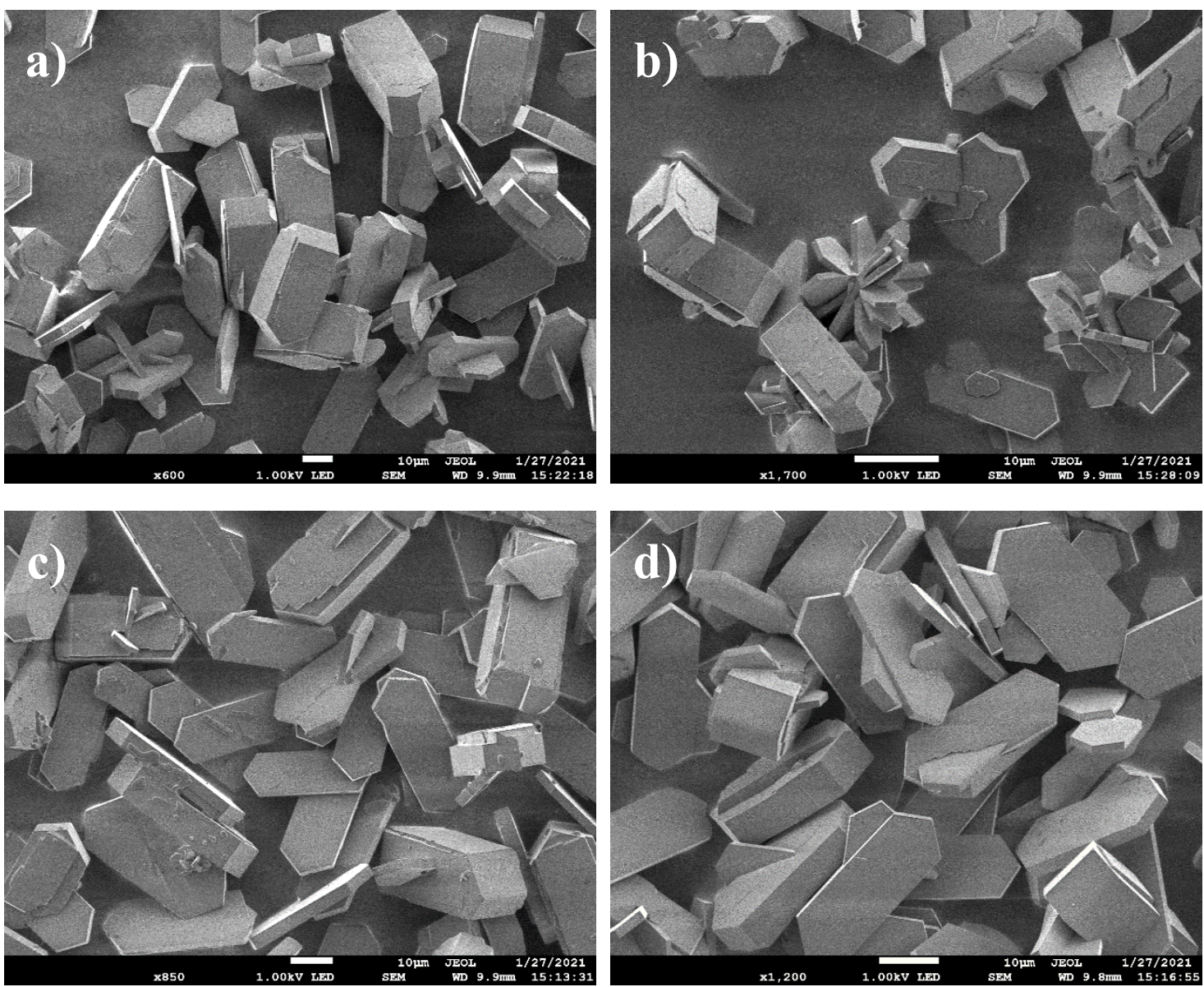

Figure 3. SEM of silicalite-1 crystallized from acidic hydrogels of the composition $1 \mathrm{SiO}_{2}: 0.50$ TPABr: $0.16 \mathrm{NH}_{4} \mathrm{~F}$ : $0.37 \mathrm{HF}: 30 \mathrm{H}_{2} \mathrm{O}$ with additional $\mathrm{NaCl}$ and $\mathrm{KCl}$ : a) $0.1 \mathrm{NaCl}$ (Sample AN\#1); b) $0.2 \mathrm{NaCl}(\mathrm{AN \# 2}) ; \mathrm{c}) 0.1 \mathrm{KCl}(\mathrm{AK \# 1})$, and d) $0.2 \mathrm{KCl}(\mathrm{AK \# 2})$.

\subsection{Impact of seed-type on the silicalite-1 formation}

The low nucleation rate in acidic hydrogels results in the formation of large crystals, which in many cases are not appropriate for practical needs because of the long diffusion path. In addition, such a synthesis is too long that also limits its practical use. These drawbacks motivated us to employ nuclei of a foreign source, i.e., to employ seeds and thus to control the zeolite crystal sizes and crystallization time.

The seed efficiency in zeolite synthesis strongly depends on their size and uniform distribution in the initial gel [35]. Therefore, we use three types of seeds and compare their effectiveness, i.e., 1) conventional micron-sized silicalite-1 prepared in a basic medium; 2) nano-crystalline silicalite-1, and 3) clear colloidal precursor gel that yields nano-crystals upon hydrothermal crystallization [36, 37]. The results are elaborated in the below paragraphs.

The first seed material Ref\#B1 has been prepared according to a conventional synthesis recipe. It contains silicalite-1 crystals of 1-10 $\mu \mathrm{m}$ in length (Figure S3). The second and third seed materials SN\#1 and SN\#2 are nanosized silicalite-1, and the amorphous precursor gel particles that are not subjected to hydrothermal treatment. They have been prepared according to the literature method [36, 37]. In literature, DLS analysis showed that the precursor particles have radii of 1-10 nm, as the peak value is centered at $3 \mathrm{~nm}$. Illuminated with X-ray, the freeze-dried clear gel scatters at small $2 \theta$ angels up to ca. $9^{\circ}$, corresponding particles of smaller nanometer sizes (Figure S2a). The bulges in $2 \theta$ range of $10-15^{\circ}$ and $18-35^{\circ}$ may imply some short-range orders in the gel structures, but it does not show 
any diffraction peaks, i.e., the gel is X-ray amorphous. The same initial system was subjected to hydrothermal treatment at $90^{\circ} \mathrm{C}$ for 30 hours yielding $80-90 \mathrm{~nm}$ silicalite- 1 nanocrystals with a narrow particle size distribution. XRD pattern of the nanocrystals, which is centrifuged from its mother liquor, washed and freeze-dried, is of the pure MFI zeolite phase. The peaks are broader in comparison with conventional silicalite-1 Ref\#B1 synthesized in the basic medium. Broadening of diffraction peaks occurs indiscriminately in crystal planes of all directions, which is typical for nanocrystals. One more significant difference between the nanocrystals and the regular crystals is that they possess different symmetries and unit cell volumes. The nanocrystals have an orthorhombic symmetry, which can be indexed in the Space Group Pnma(\#62) with $a=19.94333(0.008365), b=$ $19.74893(0.00738), c=13.21964(0.004864) \AA$, cell volume $=5206.68 \AA^{3}$. The crystals synthesized in the basic medium are monoclinic in $\mathrm{P} 21 / \mathrm{n}(\# 14)$ with $\mathrm{a}=19.80438(0.011592), \mathrm{b}=19.9207(0.008181)$, $c=13.2675(0.014617) \AA, \beta=90.0504(0.09601)^{\circ}$, cell volume $=5234.25 \AA^{3}$, where e.g., the separation of (051) and (-501) peaks are indicative. The volume contraction is also typical for nanocrystals.

FTIR spectra of the silicalite-1 nanocrystals (Sample SN\#2), the freeze-dried precursor gel (Sample SCP\#2), the micron-sized crystals synthesized in the basic medium (Sample Ref\#B1) and the micronsized crystals synthesized in the acidic medium (Sample A4) are presented in Figure S2b. In the structural vibrational region between $400-800 \mathrm{~cm}^{-1}$ there are two groups of absorption bands observable: the bending vibration $\delta(\mathrm{O}-\mathrm{Si}-\mathrm{O})$ at $450 \mathrm{~cm}^{-1}$ are present for all samples; the group of bands from $500-600 \mathrm{~cm}^{-1}$ with fine structures is seen with all crystalline samples, which are attributed to vibrations of pseudo-lattice structures of zeolites, i.e., rings and chains of various structures [22, 24]. Noticeable is that the bands are less resolved for the nanocrystal. It is resolved to some fine structures for the crystal obtained in the basic medium. Furthermore, the resolution is substantial for the crystals obtained in acidic media. Not only the band of double 5 -rings at $550 \mathrm{~cm}^{-1}$ appears $[25$, $26]$, in the region of $500-600 \mathrm{~cm}^{-1}$ there are a group of additional bands of various zeolitic structure sub-units. For the freeze-dried clear precursor gel, corresponding bands are less resolved but still clearly observable. They are somewhat broadened and extend to $700 \mathrm{~cm}^{-1}$. This indicates that some framework structures, i.e., zeolitic embryos, already exist in the X-ray amorphous gel. The presence of structural units in the silicalite-1 precursor inspired us to use these semi-formed zeolitic species as seeds, too.

The ability of conventional micron-sized crystals (Ref\#B1) to promote silicalite-1 crystallization in an acidic medium was studied. Figure S3 shows SEM pictures of the seeds and the crystalline products obtained with different amounts of seeds added to the gel preparations. A gel with composition 1 $\mathrm{SiO}_{2}$ : 0.50 TPABr: $0.15 \mathrm{NH}_{4} \mathrm{~F}: 0.37 \mathrm{HF}: 30 \mathrm{H}_{2} \mathrm{O}$ and with $\mathrm{pH}=2.56$ was employed. The silica source was Ludox AS40. The system produced $200 \mu \mathrm{m}$ crystals in 15 days. Gel pH did not change substantially after adding $1 \mathrm{wt} . \%, 2 \mathrm{wt} . \%$, and $3 \mathrm{wt} \%$ seeds. All three syntheses with seeds were completed in 5 days, compared to 15 days without seeding. An acceleration of the crystallization rate by seeding is obvious. The seed crystals possess the plate-like morphology with crystal lengths scattering from ca. $1 \mu \mathrm{m}$ to over $10 \mu \mathrm{m}$, populated towards the lower end. The products of the seeded syntheses are averagingly bigger, in the range of $3-10 \mu \mathrm{m}$ populated towards the higher end. The sizes and morphology are not sensitive to the seeding amounts. Similarly to the seed crystals, the product exhibit a wide particle size distribution. Most of the crystals are heavily intergrown. The variation of seed content between 1 and $3 \mathrm{wt} . \%$ does not change the size, morphology, and level of agglomeration of crystalline products. A crystal size control is hardly achievable by using this kind of seed (Figure S3).

The colloidal silicalite-1 nanocrystals with size $80-90 \mathrm{~nm}$ in the mother liquor have also been employed as seeds in the acidic medium synthesis. A starting acidic gel of the composition $1 \mathrm{SiO}_{2}$ : $0.50 \mathrm{TPABr}: 0.16 \mathrm{NH}_{4} \mathrm{~F}: 0.36 \mathrm{HF}: 30 \mathrm{H}_{2} \mathrm{O}$ was prepared using Silica sol 30 as the silica source. The gel $\mathrm{pH}$ is 2.96 . It crystallizes into extremely large $(300-500 \mu \mathrm{m}$ and $50 \mu \mathrm{m}$ bimodal $)$ silicalite-1 crystals at $160^{\circ} \mathrm{C}$ for 22 days, as described above. The suspension of silicalite- 1 nanocrystals obtained by hydrothermal treatment without further processing was added to the acidic gel as the seed content was 2 wt.\% on silica base. The nanosized silicalite-1 suspension was used as-prepared, without purification. Thus, together with the nano silicalite-1, semi-formed sub-nanometer precursors that 
contain zeolite framework information may also present. The seeded acidic gel has a $\mathrm{pH} 3.27$. It completes the hydrothermal crystallization at $160^{\circ} \mathrm{C}$ in 15 days, comparing 22 days without seeding. Figure 4 shows the SEM pictures of the freeze-dried seeds and the products. The seeds are spherical particles wth a mean diameter of $80-90 \mathrm{~nm}$. Thus seeded system yields well-developed crystals with flat surfaces and sharp edges. The crystal length is in the range of $300-500 \mathrm{~nm}$. The crystal size of the product is not much bigger than the seed. Therefore, the colloidal suspension of nanosized silicalite-1 is a very effective seeding material, speeding up the crystallization and reducing the crystal size.

A portion of the nano-crystals has been centrifuged from the mother liquor, washed, re-dispersed in water, and used as seeds. In this experiment, the gel $\mathrm{pH}$ is 2.78 . The product crystallized in 10 days in bigger crystals of lengths between $5-8 \mu \mathrm{m}$, providing highly intergrown crystallites. Worked-up crystals as seeds were less active than the fresh ones suspending in the mother liquor. They reduced the crystallization time, but were less effective in reducing the crystal size.
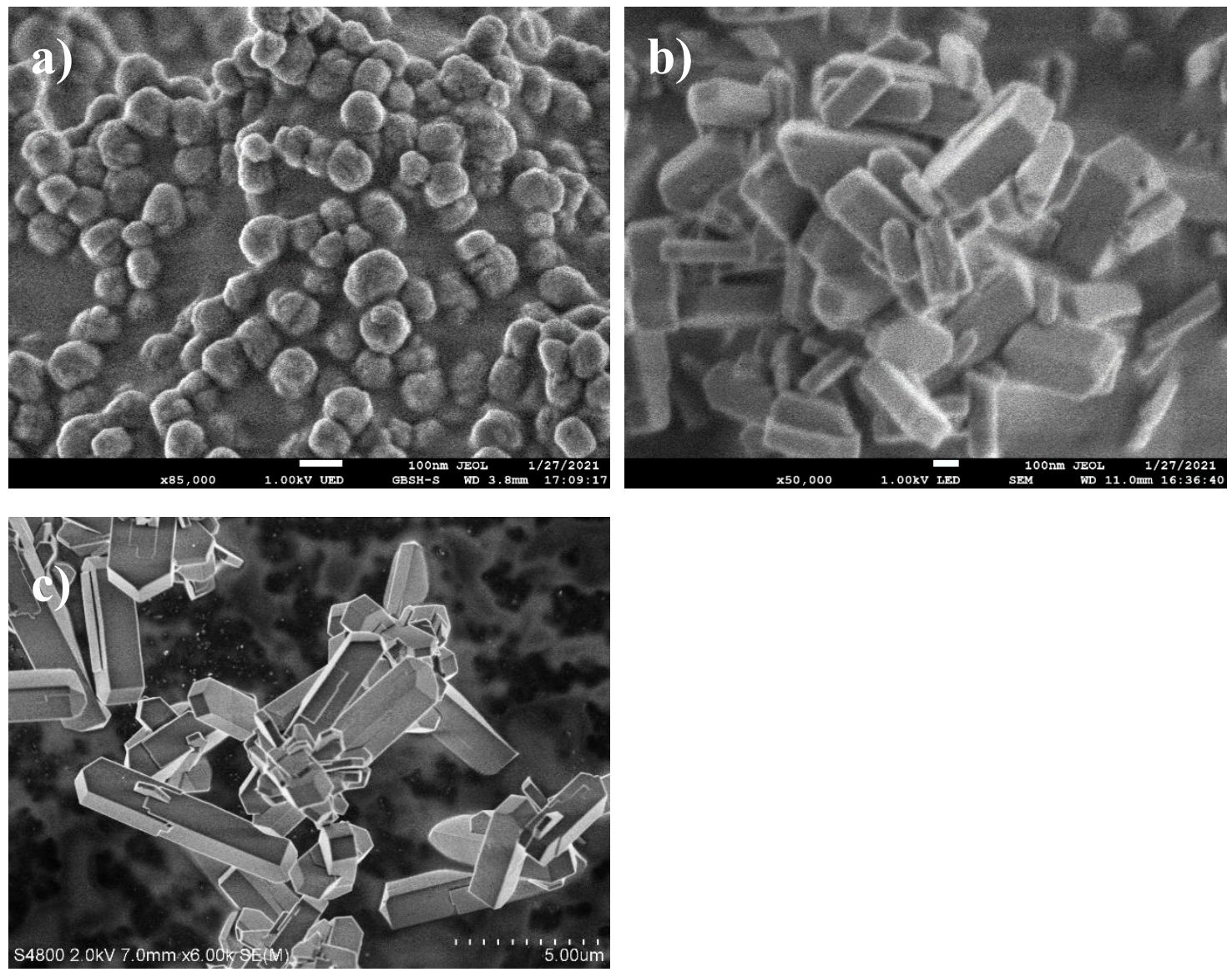

Figure 4. SEM of a) the silicalite-1 nanocrystals used as seeds (Sample SN\#2); b) silicalite-1 crystals synthesized from acidic hydrogel system using colloidal nanocrystals in the mother liquor as seeds (ASN1\#1); and c) using washed and freeze-dried nanocrystals as seeds (ASN2\#1). In both syntheses, the seeding amounts are $2 \mathrm{wt} . \%$ based on $\mathrm{SiO}_{2}$ contents.

The clear precursor, which is X-ray amorphous, and its gel particles feature zeolitic structures, has been tested as seeds. The experiments start with the same acidic hydrogel of the composition $1 \mathrm{SiO}_{2}$ : 0.50 TPABr: $0.16 \mathrm{NH}_{4} \mathrm{~F}: 0.36 \mathrm{HF}: 30 \mathrm{H}_{2} \mathrm{O}$ using Silica sol 30 as a silica source that crystallizes into bi-modulated crystals of $300-500 \mu \mathrm{m}$ and around $50 \mu \mathrm{m}$ in 22 days. Mixing the nano-silicalite- 1 clear precursor gel with this acidic gel at the amounts of 1,2 , and $3 \mathrm{wt} . \%$ of the $\mathrm{SiO}_{2}$ content, the obtained acidic hydrogels have $\mathrm{pH}$ values of $3.35,3.57$, and 3.75 , respectively. The seeding with the clear 
precursor gel has indeed accelerated the crystallization. Highly crystalline MFI-type materials have been obtained at $160^{\circ} \mathrm{C}$ in 14 days. Furthermore, the mean crystal lengths of the products of these gels are ca. 200, 150, and $100 \mu \mathrm{m}$, respectively (Figure S4), which are significantly smaller and more uniform than the un-seeded products. And, the crystals become smaller with increasing amounts of seeds. These results unambiguously prove that the clear gel acts as seeds and promotes the formation of silicalite-1 in the acidic medium. However, its role in reducing the crystal sizes is less effective than the nanocrystals.

A comparative experiment has been performed using Ludox AS-40 colloidal silica instead of Silica sol 30. The gel composition was $1 \mathrm{SiO}_{2}: 0.50 \mathrm{TPABr}: 0.15 \mathrm{NH}_{4} \mathrm{~F}: 0.37 \mathrm{HF}: 30 \mathrm{H}_{2} \mathrm{O}$, and had a liquid $\mathrm{pH}$ 2.56. The crystallization of silicalite- 1 with a mean size of $200 \mu \mathrm{m}$ in length took 15 days using this gel without seeding. Then, two types of seeds were applied, i.e., the amorphous clear precursor gel and the nanocrystal suspension. Adding the amorphous clear precursor gel as seeds $(2 \mathrm{wt} . \%$ on $\mathrm{SiO}_{2}$ base, gel $\mathrm{pH} 3.50$ ) speeds up the completion of crystallization to 6 days, and the products are crystals of $20-30 \mu \mathrm{m}$ in length. The use of $2 \mathrm{wt} . \%$ nano-crystalline seeds in the mother liquor (gel $\mathrm{pH} 3.60)$ reduces the crystal time to 9 days and submicron crystalline product $(500-800 \mathrm{~nm}$ long) (Figure 5). It confirms the above observations with the other silica sol source that both types of seeds accelerated the crystallization. Furthermore, nanosized crystals in the mother liquor are more efficient if the reduction of zeolite crystal size is the target.
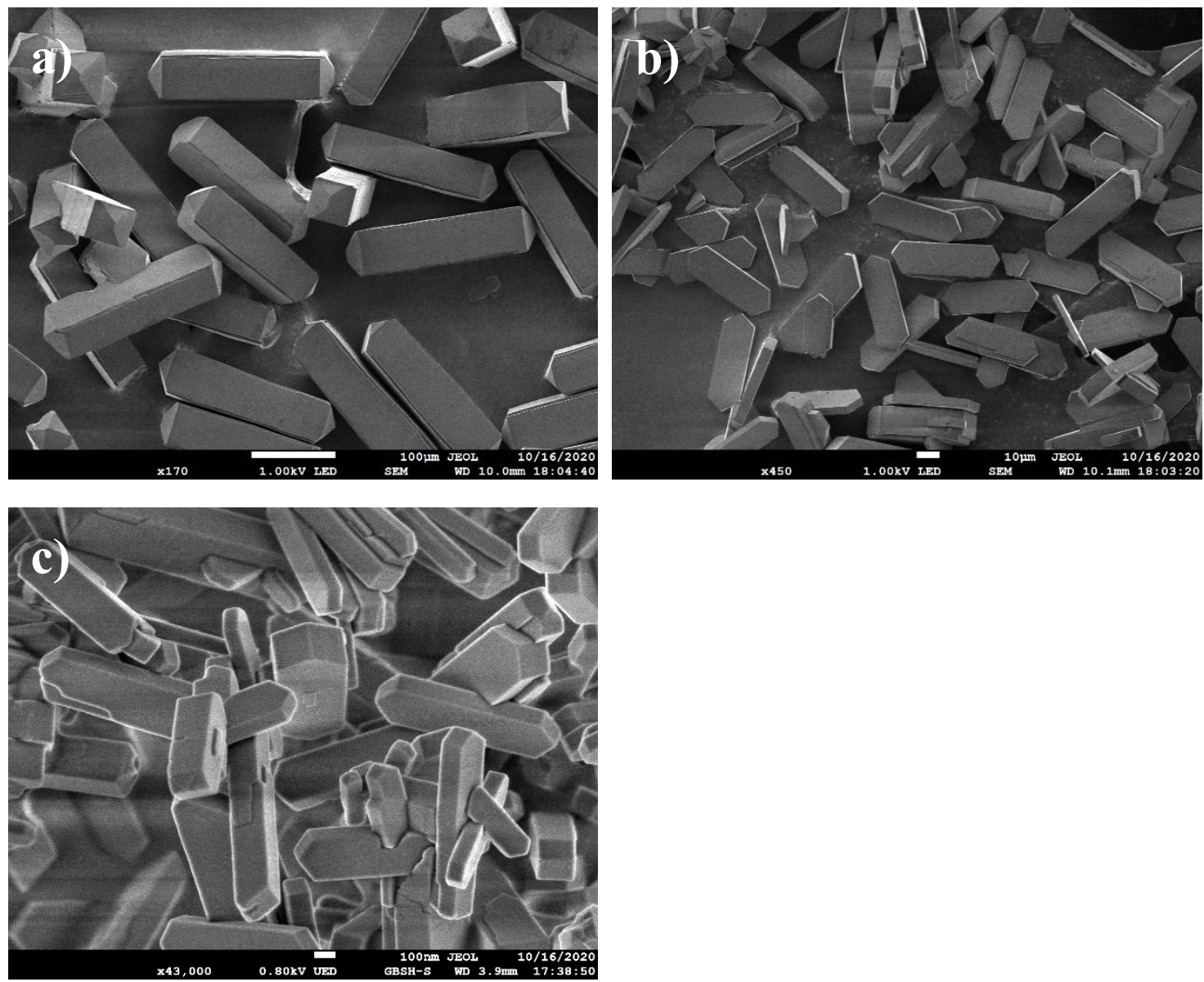

Figure 5. SEM of crystals grown from gel $1 \mathrm{SiO}_{2}$ : $0.50 \mathrm{TPABr}: 0.15 \mathrm{NH}_{4} \mathrm{~F}: 0.37 \mathrm{HF}: 30 \mathrm{H}_{2} \mathrm{O}$ : a) without seed (Sample A5); b) with X-ray amorphous clear precursor gel (ASCP\#4); and c) with colloidal nanocrystals as seeds (ASN1\#2). Seeding amounts are $2 \mathrm{wt} . \%$ based on silica.

The experimental results confirm that acidic media's slow nucleation and growth process can significantly speed up by introducing seeds. Also, the zeolite crystal size can be controlled by 
employing appropriate seeds. Table 2 summerizes the characteristics of the seeds, and the products of various synthetic recipes with the seeds. Using the clear gel containing amorphous colloidal precursors of silicalite- 1 as seeds produces crystals of tens of micrometers. Non-purified nanocrystalline seeds used together with the mother liquor facilitate formations of submicron nanocrystals and thus, they are more efficient than the amorphous precursor.

The submicron zeolites are desired in adsorption and catalytic applications to circumvent possible diffusion problems $[38,39]$. The synthesis of submicron zeolites in acidic media is an important achievement since it brings advantages to uniform hydrophobic surfaces and defect-free crystalline structures; the latter will be addressed in the following section.

Table 2. Characteristics of seeds, and the products using the seeds.

\begin{tabular}{|c|c|c|c|c|c|}
\hline $\begin{array}{l}\text { Sample } \\
\text { Name }\end{array}$ & Recipe & $\begin{array}{l}\text { Silica } \\
\text { source }\end{array}$ & $\begin{array}{l}\text { Gel } \\
\text { pH }\end{array}$ & $\begin{array}{l}\text { Crystallization } \\
\text { conditions }\end{array}$ & Product \\
\hline \multicolumn{6}{|c|}{ The nano-seeds and the conventional crystal } \\
\hline SN\#1 & $1 \mathrm{SiO}_{2}: 0.36 \mathrm{TPAOH}: 20 \mathrm{H}_{2} \mathrm{O}$ & TEOS & 12.50 & 90C, 30 hours & $\begin{array}{l}90 \mathrm{~nm} \text {, the } \\
\text { suspension }\end{array}$ \\
\hline SN\#2 & $1 \mathrm{SiO}_{2}: 0.36 \mathrm{TPAOH}: 20 \mathrm{H}_{2} \mathrm{O}$ & TEOS & 12.50 & $90 \mathrm{C}, 30$ hours & $90 \mathrm{~nm}$, the crystals \\
\hline $\mathrm{SCP} \# 2$ & $1 \mathrm{SiO}_{2}: 0.36 \mathrm{TPAOH}: 20 \mathrm{H}_{2} \mathrm{O}$ & TEOS & 12.50 & RT, 24 hours & $\begin{array}{l}0-10 \mathrm{~nm} \text {, peak at } \\
\text { ca. } 3 \mathrm{~nm}\end{array}$ \\
\hline Ref\#B1 & $1 \mathrm{SiO}_{2}: 0.12 \mathrm{TPAOH}: 60 \mathrm{H}_{2} \mathrm{O}$ & TEOS & 12.60 & $160 \mathrm{C}, 24$ hours & $1-10 \mu \mathrm{m}$ \\
\hline \multicolumn{6}{|c|}{ Using Ref\#B1 seed } \\
\hline ASB1\#1 & $\begin{array}{l}\text { 1SiO } \mathrm{S}_{2}: 0.50 \mathrm{TPABr}: 0.15 \mathrm{NH}_{4} \mathrm{~F}: 0.37 \mathrm{HF}: 30 \mathrm{H}_{2} \mathrm{O}+ \\
\text { 1wt.\% Ref\#B1 seed }\end{array}$ & $\begin{array}{l}\text { Ludox } \\
\text { AS40 }\end{array}$ & 2.47 & $160 \mathrm{C}, 5$ days & $3-10 \mu \mathrm{m}$ \\
\hline ASB1\#2 & $\begin{array}{l}\text { 1SiO } \mathrm{Si}_{2}: 0.50 \mathrm{TPABr}: 0.15 \mathrm{NH}_{4} \mathrm{~F}: 0.37 \mathrm{HF}: 30 \mathrm{H}_{2} \mathrm{O}+ \\
\text { 2wt.\% Ref\#B1 seed }\end{array}$ & $\begin{array}{l}\text { Ludox } \\
\text { AS40 }\end{array}$ & 2.53 & 160C, 5 days & $3-10 \mu \mathrm{m}$ \\
\hline ASB1\#3 & $\begin{array}{l}1 \mathrm{SiO}_{2}: 0.50 \mathrm{TPABr}: 0.15 \mathrm{NH}_{4} \mathrm{~F}: 0.37 \mathrm{HF}: 30 \mathrm{H}_{2} \mathrm{O}+ \\
\text { 3wt.\% Ref\#B1 seed }\end{array}$ & $\begin{array}{l}\text { Ludox } \\
\text { AS40 }\end{array}$ & 2.58 & $160 \mathrm{C}, 5$ days & $3-10 \mu \mathrm{m}$ \\
\hline \multicolumn{6}{|c|}{ Using SN\#1 nanocrystal suspension seed } \\
\hline ASN1\#1 & $\begin{array}{l}1 \mathrm{SiO}_{2}: 0.50 \mathrm{TPABr}: 0.16 \mathrm{NH}_{4} \mathrm{~F}: 0.36 \mathrm{HF}: 30 \mathrm{H}_{2} \mathrm{O}+ \\
2 \mathrm{wt} . \% \text { SN\#1 seed }\end{array}$ & $\begin{array}{l}\text { Silica sol } \\
30\end{array}$ & 3.27 & $160 \mathrm{C}, 15$ days & $300-500 \mathrm{~nm}$ \\
\hline ASN1\#2 & $\begin{array}{l}1 \mathrm{SiO}_{2}: 0.50 \mathrm{TPABr}: 0.15 \mathrm{NH}_{4} \mathrm{~F}: 0.37 \mathrm{HF}: 30 \mathrm{H}_{2} \mathrm{O}+ \\
2 \mathrm{wt} . \% \text { SN\#1 seed }\end{array}$ & $\begin{array}{l}\text { Ludox } \\
\text { AS40 }\end{array}$ & 3.60 & $160 \mathrm{C}, 9$ days & $500-800 \mathrm{~nm}$ \\
\hline \multicolumn{6}{|c|}{ Using SN\#2 nanocrystal seed (washed and redispersed) } \\
\hline ASN2\#1 & $\begin{array}{l}1 \mathrm{SiO}_{2}: 0.50 \mathrm{TPABr}: 0.16 \mathrm{NH}_{4} \mathrm{~F}: 0.36 \mathrm{HF}: 30 \mathrm{H}_{2} \mathrm{O}+ \\
2 \mathrm{wt} . \% \text { SN\#2 seed }\end{array}$ & $\begin{array}{l}\text { Ludox } \\
\text { AS40 }\end{array}$ & 2.78 & $160 \mathrm{C}, 10$ days & $5-8 \mu \mathrm{m}$ \\
\hline \multicolumn{6}{|c|}{ Using SCP\#2 clear gel seed } \\
\hline ASCP\#1 & $\begin{array}{l}1 \mathrm{SiO}_{2}: 0.50 \mathrm{TPABr}: 0.16 \mathrm{NH}_{4} \mathrm{~F}: 0.36 \mathrm{HF}: 30 \mathrm{H}_{2} \mathrm{O}+ \\
1 \mathrm{wt} . \% \text { SCP\#2 seed }\end{array}$ & $\begin{array}{l}\text { Silica sol } \\
30\end{array}$ & 3.35 & 160C, 14 days & $200 \mu \mathrm{m}$ \\
\hline ASCP\#2 & $\begin{array}{l}1 \mathrm{SiO}_{2}: 0.50 \mathrm{TPABr}: 0.16 \mathrm{NH}_{4} \mathrm{~F}: 0.36 \mathrm{HF}: 30 \mathrm{H}_{2} \mathrm{O}+ \\
2 \mathrm{wt} . \% \text { SCP\#2 seed }\end{array}$ & $\begin{array}{l}\text { Silica sol } \\
30\end{array}$ & 3.57 & 160C, 14 days & $150 \mu \mathrm{m}$ \\
\hline ASCP\#3 & $\begin{array}{l}1 \mathrm{SiO}_{2}: 0.50 \mathrm{TPABr}: 0.16 \mathrm{NH}_{4} \mathrm{~F}: 0.36 \mathrm{HF}: 30 \mathrm{H}_{2} \mathrm{O}+ \\
3 \mathrm{wt} . \% \text { SCP\#2 seed }\end{array}$ & $\begin{array}{l}\text { Silica sol } \\
30\end{array}$ & 3.75 & 160C, 14 days & $100 \mu \mathrm{m}$ \\
\hline ASCP\#4 & $\begin{array}{l}1 \mathrm{SiO}_{2}: 0.50 \mathrm{TPABr}: 0.15 \mathrm{NH}_{4} \mathrm{~F}: 0.37 \mathrm{HF}: 30 \mathrm{H}_{2} \mathrm{O}+ \\
2 \mathrm{wt} . \% \text { SCP\#2 seed }\end{array}$ & $\begin{array}{l}\text { Ludox } \\
\text { AS40 }\end{array}$ & 3.50 & 160C, 6 days & $20-30 \mu \mathrm{m}$ \\
\hline
\end{tabular}

\subsection{Synthesis medium - crystal properties relationship}

The physicochemical properties of silicalite-1 samples synthesized in conventional (basic medium), fluoride route (neutral medium), and acidic medium were compared with special attention paid to the point defects in the framework. Our interest in this feature is due to the fact that the number of zeolite framework defects results in significant differences in the material's surface properties and structural stabilities. TG/DTA, in situ XRD, ${ }^{29} \mathrm{Si}$ and ${ }^{19} \mathrm{~F}$ MAS NMR, and in situ FTIR characterizations were employed in this study. The methods sensitive to short-range structures revealed obvious differences between the acidic medium synthesized and the reference materials.

TG/DTA curves of the 3 representative as-synthesized samples are illustrated in Figure S5: a) submicron-sized crystal obtained in the acidic medium; b) micron-crystals obtained in the neutral medium; and c) micron-crystals obtained in the basic medium. All three samples lose weights of 
about 12 wt. $\%$ between $380-430^{\circ} \mathrm{C}$, with the exothermic peaks at 410,405 and $420^{\circ} \mathrm{C}$, respectively, corresponding to the combustion of SDA. The fact that they contain a similar amount of SDA implies that they possess similar crystallinity. Next events occur at higher temperatures. At $1360^{\circ} \mathrm{C}$ the DTA curve of the acidic sample exhibits an endothermic signal with a sharp peak and a broader feature beneath it. This signal corresponds to the collapse of the zeolite framework and the conversion into a dense $\mathrm{SiO}_{2}$ phase. Similar behavior showed the sample synthesized in neutral medium, with the peak temperature at $1350^{\circ} \mathrm{C}$. For the conventional silicalite- 1 obtained in the basic system, the framework collapse happens at $1315^{\circ} \mathrm{C}$, and the peak of phase transformation is at $1360^{\circ} \mathrm{C}$. Although the difference in the stability of the three samples is minor, it could be stated that the materials crystallized in acidic and neutral media possess a more stable framework than the one obtained in the basic system.

Figure 6 shows TG/DTA curves of the same three samples after calcination at $540^{\circ} \mathrm{C}$ in air, and rehydrated at room temperature in air of $70 \%$ humidity. All three samples are very much hydrophobic, with max 4.7 wt.\% water saturated at ambient conditions. However, differences in adsorbed water are still apparent among the samples during the deep dehydration process from room temperature to $600^{\circ} \mathrm{C}$. The material synthesized in the traditional basic system (Sample Ref\#B1) loses water in 2 observable steps: the desorption of weakly bound water occurs up to $100^{\circ} \mathrm{C}$ at an amount of ca. 2.5 wt.\%; on DTA curve, there is a detectable negative heat flow from upto $100^{\circ} \mathrm{C}$; and additional dehydration of $2.2 \mathrm{wt} . \%$ lasts gradually until $600^{\circ} \mathrm{C}$. The total weight loss of the material synthesized in the near-neutral medium (Ref\#N2) to $600^{\circ} \mathrm{C}$ is ca. $2.5 \mathrm{wt} . \%$, too. But the 2 steps are less resolved. The water desorption amount before $100^{\circ} \mathrm{C}$ is lower at ca. $0.75 \mathrm{wt} . \%$, without an obvious heat incident in DTA. The acidic medium synthesized material (ASN1\#2) distinguishes itself from the references with the total weight loss of only $1.0 \mathrm{wt} . \%$ to $600^{\circ} \mathrm{C}$. The dehydration proceeds smoothly that the accompanying heat effect is barely observable. The results imply that the acidic medium product is more hydrophobic than the neutral and basic medium synthesized materials.
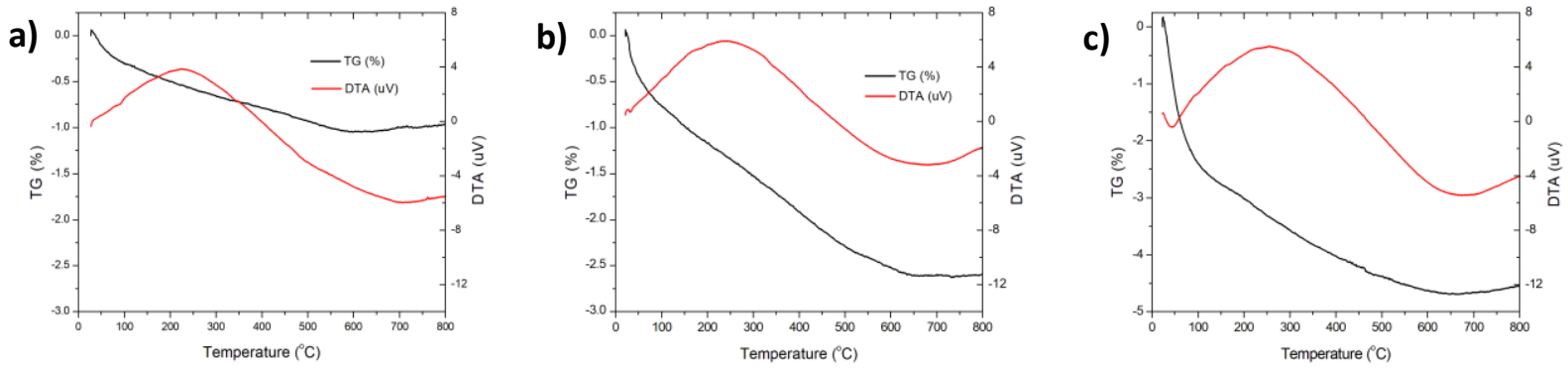

Figure 6. TG/DTA of calcined and rehydrated silicalite-1 crystallized in a) acidic (Sample ASN1\#2); b) near-neutral (Ref\#N2) and c) basic medium (Ref\#B1).

Furthermore, the same three samples have been subjected to in situ thermic XRD tests in ambient air (70\% humidity). The XRD patterns are shown in Figure S6a-S6c. The submicron silicalite-1 synthesized in the acidic medium experiences two significant phase changes, at $350^{\circ} \mathrm{C}$ and $1350^{\circ} \mathrm{C}$, respectively. At room temperature, it is orthorhombic. Upon heating from room temperature until $300^{\circ} \mathrm{C}$ the unit cell volume expands. The combustion of SDA occurs between 350 and $400^{\circ} \mathrm{C}$. After SDA removal, the symmetry is reduced to monoclinic. And a negative cell expansion is observed between 400 and $1300^{\circ} \mathrm{C}$, similar to other zeolite materials [40]. Refined cell parameters are listed in Table S2. At $1350^{\circ} \mathrm{C}$, the zeolite framework has partly collapsed, with peak intensities dropping to less than a half. At $1400^{\circ} \mathrm{C}$, the zeolite's X-ray diffractions are barely observable, and the diffraction peaks of cristobalite appear. At 1450 and $1500^{\circ} \mathrm{C}$, the zeolite diffraction peaks completely disappear, while those of cristobalite become more intense. The sample synthesized in the neutral medium behaves similarly upon heating in air. The SDA removal lasts longer, between 350 and $450^{\circ} \mathrm{C}$. The framework collapse is observable at $1350^{\circ} \mathrm{C}$ as well, but at $1400^{\circ} \mathrm{C}$ a half of the initial diffraction 
intensities remains. It turns completely to cristobalite at $1500^{\circ} \mathrm{C}$. In this series of experiments, the neutral system synthesized silicalite-1 appears more robust than the acidic counterpart, owing perhaps to the fact that the crystal sizes are bigger.

The reference silicalite- 1 synthesized in the basic medium is monoclinic in the whole temperature range. The crystal symmetry does not change until its structure collapse. The SDA combustion starts at $350^{\circ} \mathrm{C}$ as well and continues up to $450^{\circ} \mathrm{C}$. There is a thermal expansion as well for the assynthesized material below the temperature of SDA removal. Above $450^{\circ} \mathrm{C}$, the cell volume contracts upon heating until $1250^{\circ} \mathrm{C}$. The zeolite structure collapses at $1300^{\circ} \mathrm{C}$, i.e., $50^{\circ} \mathrm{C}$ lower than the crystal out of the acidic and neutral media, despite that the crystal sizes are bigger. At $1400^{\circ} \mathrm{C}$ it transforms into cristobalite.

The heating test shows that the crystals obtained in acidic and neutral media are more stable than the crystals synthesized in the traditional basic media, although the crystal size of the latter sample is bigger than the former two.

Both TG/DTA of the as-synthesized materials and in situ XRD reveal the bulk properties of the samples. They can display the differences of silicalite-1 samples synthesized in the acidic and the neutral media from the conventional material out of the basic system. However, these analyses did not distigush the acidic from the neutral medium synthesized crystals. Therefore, methods to characterize short-range structures, such as ${ }^{29} \mathrm{Si}$ MAS NMR and FTIR, are required to shed light on the intimate structure of different samples.

In general, high-silica zeolites synthesized via the "fluoride route" in neutral systems have fewer point defects and better integral frameworks than the materials synthesized in traditional basic media. This fact has been proven, e.g., by ${ }^{29} \mathrm{Si}$ MAS NMR spectroscopy, which shows higher resolutions of the $\mathrm{Q}^{4}$ (Si-(O-Si)4) signals [41] for the materials obtained via the fluoride rout [12, 42]. Noteworthy, the synthesis in acidic medium results in a zeolite product of a higher ${ }^{29} \mathrm{Si}$ MAS NMR resolution than that in neutral medium. Figure 7 shows the ${ }^{29} \mathrm{Si}\left\{{ }^{1} \mathrm{H}\right\}$ cross-polarization (CP) MAS spectra of the samples of various sizes crystallized in the acidic medium and neutral medium, i.e., Samples ASN1\#2, ASCP\#4, A5 and Ref\#N1. For all the samples, the $\mathrm{Q}^{4}$ sites are relatively well resolved, and few or no $\mathrm{Q}^{3}$ sites are observed. This is due to the presence of fluoride. Because of the presence of $\mathrm{F}^{-}$cations, the siloxy/silanols defects often observed in the materials synthesized in the traditional basic medium using hydroxyl anions as a mineralizing agent are not needed to balance the positive charge of the $\mathrm{TPA}^{+}$cation [43]. The spectral resolution of the samples synthesized in acidic media is clearly higher than the one observed for the sample synthesized in near-neutral $\mathrm{pH}$. The spectra obtained can be fitted with twelve peaks corresponding to the distinct tetrahedral sites in Pnma symmetry (Figure S7) [44]. By comparing the acidic synthesized samples (Sample A5 $200 \mu \mathrm{m}$, ASCP\#4 20-30 $\mu \mathrm{m}$, ASN1\#2 500-800 $\mathrm{nm}$ ), we observe a decreasing local order when going downwards with the crystal sizes. However, even the smallest acidic medium synthesized crystals (ca. 500-800 nm) exhibit a higher local structure order than the neutral counterpart of a much bigger size. 


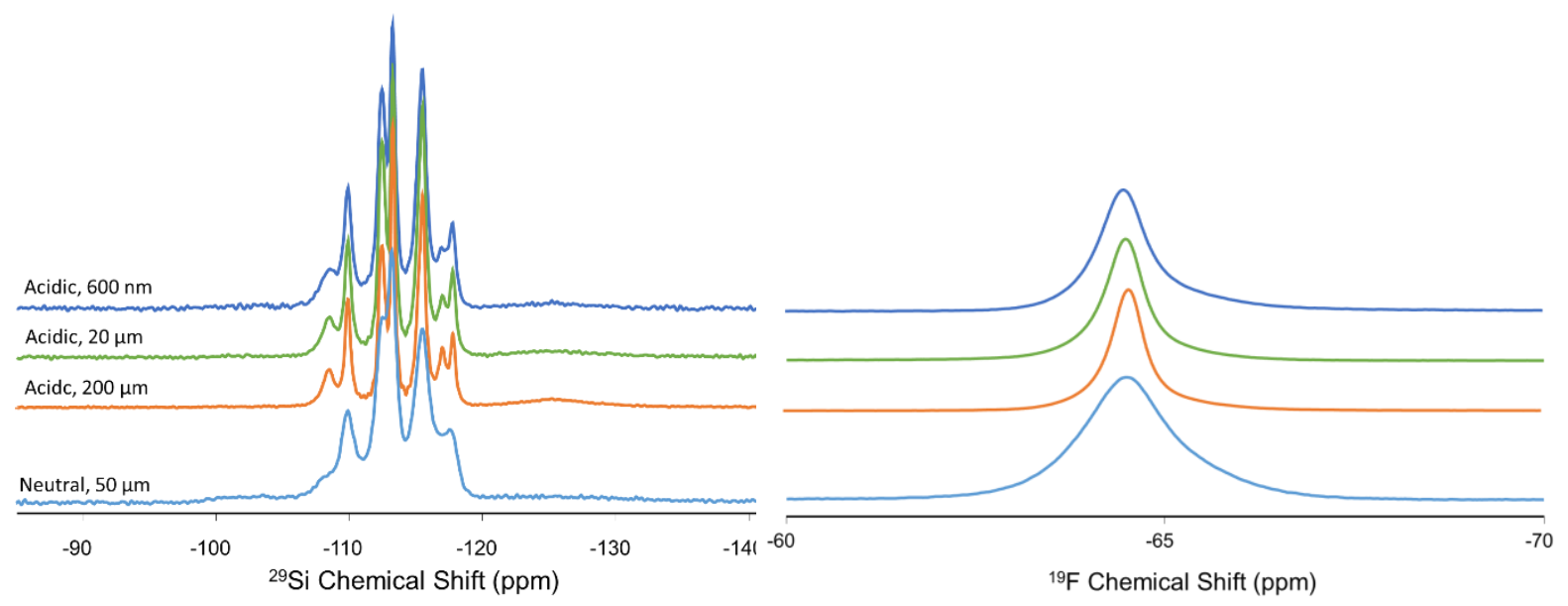

Figure 7. ${ }^{29} \mathrm{Si}\left\{{ }^{1} \mathrm{H}\right\}$ cross-polarization (CP) magic-angle spinning (MAS) NMR spectra and ${ }^{19} \mathrm{~F}$ MAS NMR spectra of Silicalite-1 crystals of various sizes synthesized in acidic and neutral media (Samples ASN1\#2, ASCP\#4, A5 and Ref\#N1).

The fluoride environment also shows the same broadening trend with decreasing sizes of the acidic medium synthesized crystals, as shown by ${ }^{19} \mathrm{~F}$ MAS NMR (Figure 7). And the peak for the neutral crystallized sample is broader than all acidic medium synthesized samples. Furthermore, in all samples, the fluoride anions occupy the well-known $\left[4^{1} 5^{2} 6^{2}\right]$ cage [45]. This is in line with the broad resonance at $-125 \mathrm{ppm}$ in the ${ }^{29} \mathrm{Si}$ NMR spectra (Figure 7). Furthermore, the same chemical shift anisotropy parameters have been obtained for ${ }^{19} \mathrm{~F}$ nuclei $\left(\delta_{\text {iso }}=-64.47 \mathrm{ppm}, \Delta_{\mathrm{CSA}}=-43.83 \mathrm{ppm}, \eta_{\mathrm{CSA}}\right.$ $=0.96$ ) [46]. The five peaks in the ${ }^{29} \mathrm{Si}\left\{{ }^{19} \mathrm{~F}\right\}$ CP MAS spectra corresponding to the small cage occupied by the fluoride shown in Figure S8. ${ }^{19}$ F MAS NMR with Hahn Echo reveals as well the same broadening order for the samples. A fit confirms the location of $\mathrm{F}^{-}$ion, as well (Figure S9).

Figure 8 shows FTIR spectra in the -OH stretching region of the micron-sized crystals synthesized in the neutral medium, as well as the sub-micron and the 20-micron crystals synthesized in the acidic media, that have been recorded along with dehydration treatments in flowing Ar from room temperature to $600^{\circ} \mathrm{C}$. The self-sustaining pellets of the three samples have the same density of 15 $\mathrm{mg} / \mathrm{cm}^{2}$, which allows comparing the optical intensities of respective absorption bands. At the hydrated states at $25^{\circ} \mathrm{C}$, all samples exhibit three bands: the sharp one at $3745 \mathrm{~cm}^{-1}$ belongs to $v(-\mathrm{O}-\mathrm{H})$ of isolated $\mathrm{Si}-\mathrm{OH}$ groups that exposed on the outer surfaces (external silanols); the shoulder at around $3680 \mathrm{~cm}^{-1}$ is attributed to silanols existing inside MFI channels that are weakly H-bonded to adsorbed $\mathrm{H}_{2} \mathrm{O}$ or with each other; the intense and broadband around $3400 \mathrm{~cm}^{-1}$ belongs to adsorbed $\mathrm{H}_{2} \mathrm{O}$ that are strongly H-bonded with each other, and eventually with silanols at framework defects [42, 47, 48]. The intensities of the external silanol bands at $3745 \mathrm{~cm}^{-1}$ barely change upon dehydration up to $600^{\circ} \mathrm{C}$ for all three samples.

For the sample crystallized in the neutral medium (Sample Ref\#N2), when the water band at $3400 \mathrm{~cm}^{-1}$ gradually disappears upon dehydration, a band beneath it at $3500 \mathrm{~cm}^{-1}$ emerges. This band becomes less intense with increasing dehydration temperatures. However, the band is still observable at $600^{\circ} \mathrm{C}$, indicating that a tiny but not negligible amount of silanol nests exist at framework pointdefects [47]. Similarly, the band of internal silanol at $3680 \mathrm{~cm}^{-1}$ loses its intensity upon dehydration, but it is not completely removable at $600^{\circ} \mathrm{C}$, either. It blue-shifts to a weak shoulder of the $3745 \mathrm{~cm}^{-1}$ band. This implies that some terminal Si-OH groups in the channels (or close to channel mouths) are quite stable and do not become fully linked to bridging Si-O-Si upon heating to $600^{\circ} \mathrm{C}$ [47].

The 20-micron crystals obtained in the acidic medium (Sample ASCP\#4) behave similarly to the neutral sample upon dehydration. The band intensity of silanol nests at point-defects at $3500 \mathrm{~cm}^{-1}$ is similar, and one of the internal nonbridging silanols at $3680 \mathrm{~cm}^{-1}$ is even more intense. The submicron crystals synthesized in the acidic medium (Sample ASN1\#2) possess remarkable framework integrity compared to both reference samples. Upon dehydration, the water band disappears 
completely. The $3700 \mathrm{~cm}^{-1}$ shoulder of the internal nonbridging silanols becomes barely observable at $600^{\circ} \mathrm{C}$ as well. The crystals are, in fact, free of point defects.
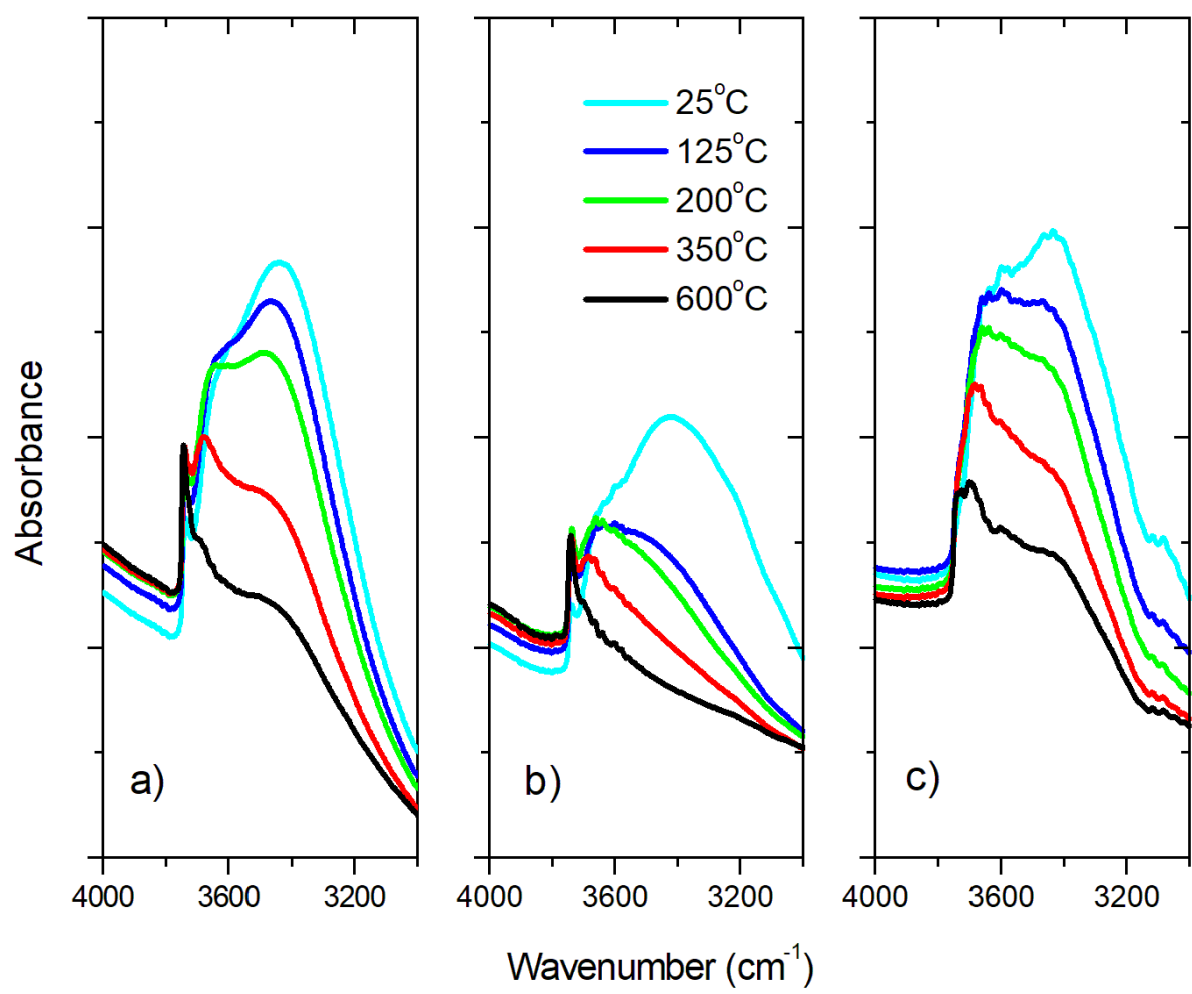

Figure 8. FTIR spectra of the crystals of silicalite- 1 synthesized a) in neutral medium with crystal sizes of 1.5-1.8 $\mu \mathrm{m}$ (Sample Ref\#N2); b) in acidic medium with crystal sizes of $500-800 \mathrm{~nm}$ (ASN1\#2); and c) in acidic medium with crystal sizes of 20-30 $\mu \mathrm{m}$ (ASCP\#4).

\section{Conclusions}

Crystallization of silicalite- 1 in acidic media ( $\mathrm{pH}=2-4)$ was successfully conducted using different silica sources. Ludox AS40 was found the most appropriate in terms of product crystallinity, time of synthesis, and crystal size control. In general, the zeolite synthesis in an acidic medium is long $(>15$ days), and the crystals are large $(>200 \mu \mathrm{m})$. The introduction of small amounts of $\mathrm{NaCl}$ and $\mathrm{KCl}$ in the precursor gel reduced the crystal sizes to less than $80 \mu \mathrm{m}$, but cannot speed up the crystallization rate.

A substantial reduction of crystal size and crystallization time was achieved by seeding the initial system. Three types of seeds were employed, i.e., micron-sized crystals, nanosized crystals and X-ray amorphous silicalite-1 precursor gel. Amongst different seeds, the nanosized silicalite-1 seeds introduced as colloidal non-purified suspension provided the best results, i.e., silicalite- 1 crystals of a few hundred nanometers in length (300-500 nm, or 500-800 nm, depending on Si sources) can be obtained in 9 days. This method, producing submicron crystallites, is particularly important because zeolites of this size are desired in adsorption and catalytic applications to circumvent possible diffusion problems. However, seeding with regular micron-size silicalite-1 is also practical. The products are 3-10 $\mu \mathrm{m}$ crystals synthesized within 5 days. The use of X-ray amorphous silicalite-1 precursor gel accelerates the crystallization process (6-14 Days). However, the synthesized product contains relatively large crystals $(20-200 \mu \mathrm{m})$. 
The physicochemical analysis of the samples synthesized in acidic medium showed important practical advantages regarding neutral and basic medium synthesized counterparts. The structural integrity of submicron silicalite-1 crystals is higher than that of neutral medium synthesized micronsized crystals. This material exhibits the lowest number of point defects, high local structure ordering, uniform hydrophobic surface, and high thermal stability. Moreover, the use of appropriate seeds allows the crystal growth process to be substantially shortened.

\section{Supplementary Information}

A complete list of silicalite-1 crystals that have been synthesized and are discussed in the paper; XRD patterns and in situ XRD patterns of selected samples; Further SEM, FTIR, NMR characterization results are provided as Supplementary Information. The following files are available free of charge.

SupplementaryInformation.pdf

\section{CRediT authorship contribution statement}

X. Yang: Investigation, Writing - original draft. E. Dib, Q. Lang, H. Guo, G. Fu, J. Wang, Q. Yi, H. Zhao: Investigation. V. Valtchev: Conceptualization, Supervision, Writing - review \& editing, Funding acquisition.

\section{Declaration of competing interest}

The authors declare that they have no known competing financial interests or personal relationships that could have appeared to influence the work reported in this paper.

\section{Acknowledgment}

The ZeoMat Group acknowledges the starting grant provided by QIBEBT. V.V. and X.Y acknowledge the collaboration in the framework of the Sino-French joint laboratory "Zeolites".

\section{References}

[1] Y. Li, L. Li, J. Yu, Applications of Zeolites in Sustainable Chemistry, Chem, 3 (2017) 928-949.

[2] C. Martínez, A. Corma, Inorganic molecular sieves: Preparation, modification and industrial application in catalytic processes, Coordination Chemistry Reviews, 255 (2011) 1558-1580.

[3] M. Zaarour, B. Dong, I. Naydenova, R. Retoux, S. Mintova, Progress in zeolite synthesis promotes advanced applications, Microporous and Mesoporous Materials, 189 (2014) 11-21. [4] G.A. Ozin, A. Kuperman, A. Stein, Advanced Zeolite, Materials Science, Angewandte Chemie International Edition in English, 28 (1989) 359-376.

[5] B.M. Weckhuysen, J. Yu, Recent advances in zeolite chemistry and catalysis, Chemical Society Reviews, 44 (2015) 7022-7024.

[6] E. Taarning, C.M. Osmundsen, X. Yang, B. Voss, S.I. Andersen, C.H. Christensen, Zeolite-catalyzed biomass conversion to fuels and chemicals, Energy \& Environmental Science, 4 (2011) 793-804.

[7] E.M. Flanigen, Molecular sieve zeolite technology - The first twenty-five years, Pure \& Applied Chemistry, 52 (1980) 21.

[8] R.M. Milton, Molecular Sieve Science and Technology, Zeolite Synthesis, American Chemical Society1989, pp. 1-10. 
[9] E.M. Flanigen, Chapter 2 Zeolites and molecular sieves: An historical perspective, in: H. van Bekkum, E.M. Flanigen, P.A. Jacobs, J.C. Jansen (Eds.) Studies in Surface Science and Catalysis, Elsevier2001, pp. 11-35.

[10] G.T. Kokotailo, S.L. Lawton, D.H. Olson, W.M. Meier, Structure of synthetic zeolite ZSM-5, Nature, 272 (1978) 437-438.

[11] P. Caullet, J.-L. Paillaud, A. Simon-Masseron, M. Soulard, J. Patarin, The fluoride route: a strategy to crystalline porous materials, Comptes Rendus Chimie, 8 (2005) 245-266.

[12] H. Koller, A. Wölker, L.A. Villaescusa, M.J. Díaz-Cabañas, S. Valencia, M.A. Camblor, Five-Coordinate Silicon in High-Silica Zeolites, Journal of the American Chemical Society, 121 (1999) 3368-3376.

[13] S.L. Burkett, M.E. Davis, Mechanism of Structure Direction in the Synthesis of Si-ZSM5: An Investigation by Intermolecular 1H-29Si CP MAS NMR, The Journal of Physical Chemistry, 98 (1994) 4647-4653.

[14] S.L. Burkett, M.E. Davis, Mechanisms of Structure Direction in the Synthesis of PureSilica Zeolites. 1. Synthesis of TPA/Si-ZSM-5, Chemistry of Materials, 7 (1995) 920-928.

[15] G. Melinte, V. Georgieva, M.-A. Springuel-Huet, A. Nossov, O. Ersen, F. Guenneau, A. Gedeon, A. Palcic, K.N. Bozhilov, P.-H. Cuong, S. Qiu, S. Mintova, V. Valtchev, 3D Study of the Morphology and Dynamics of Zeolite Nucleation, Chemistry-a European Journal, 21 (2015) 18316-18327.

[16] D. Shi, K.-G. Haw, C. Kouvatas, L. Tang, Y. Zhang, Q. Fang, S. Qiu, V. Valtchev, Expanding the Synthesis Field of High-Silica Zeolites, Angewandte Chemie International Edition, 59 (2020) 19576-19581.

[17] D. Massiot, F. Fayon, M. Capron, I. King, S. Le Calvé, B. Alonso, J.-O. Durand, B. Bujoli, Z. Gan, G. Hoatson, Modelling one- and two-dimensional solid-state NMR spectra, Magnetic Resonance in Chemistry, 40 (2002) 70-76.

[18] J. Cihlár, Hydrolysis and polycondensation of ethyl silicates. 1. Effect of $\mathrm{pH}$ and catalyst on the hydrolysis and polycondensation of tetraethoxysilane (TEOS), Colloids and Surfaces

A: Physicochemical and Engineering Aspects, 70 (1993) 239-251.

[19] M.T. Harris, R.R. Brunson, C.H. Byers, The base-catalyzed hydrolysis and condensation reactions of dilute and concentrated TEOS solutions, Journal of Non-Crystalline Solids, 121 (1990) 397-403.

[20] E. Mine, D. Nagao, Y. Kobayashi, M. Konno, Solvent Effects on Particle Formation in Hydrolysis of Tetraethyl Orthosilicate, Journal of Sol-Gel Science and Technology, 35 (2005) 197-201.

[21] M.A. Camblor, L.A. Villaescusa, M.J. Díaz-Cabañas, Synthesis of all-silica and highsilica molecular sieves in fluoride media, Topics in Catalysis, 9 (1999) 59-76.

[22] E.M. Flanigen, H. Khatami, H.A. Szymanski, Infrared Structural Studies of Zeolite Frameworks, Molecular Sieve Zeolites-I, AMERICAN CHEMICAL SOCIETY1974, pp. 201-229.

[23] E.M.K. Flaningen, H. ; Szymanski H. A., Adv. Chem. Ser. , 101 (1971) 201.

[24] M. Król, W. Mozgawa, W. Jastrzębski, K. Barczyk, Application of IR spectra in the studies of zeolites from D4R and D6R structural groups, Microporous and Mesoporous Materials, 156 (2012) 181-188.

[25] G. Coudurier, C. Naccache, J.C. Vedrine, Uses of i.r. spectroscopy in identifying ZSM zeolite structure, Journal of the Chemical Society, Chemical Communications, (1982) 14131415.

[26] P.A. Jacobs, E.G. Derouane, J. Weitkamp, Evidence for X-ray-amorphous zeolites, Journal of the Chemical Society, Chemical Communications, (1981) 591-593. 
[27] X.J. Gu, D.J. Levandier, B. Zhang, G. Scoles, D. Zhuang, On the infrared spectroscopy of SiF4 and SF6 in Ar clusters: Location of the solute, The Journal of Chemical Physics, 93 (1990) 4898-4906.

[28] H. Ooe, Y. Miyamoto, S. Kuma, N. Sasao, K. Kawaguchi, Infrared absorption spectra of SiF4 and its clusters in solid parahydrogen, Chemical Physics Letters, 631-632 (2015) 54-58. [29] T. Shimizu, M. Kumeda, H. Komatsu, Y. Yonezawa, NMR and IR studies on SiF4 molecules in a-Si:F, Journal of Non-Crystalline Solids, 77-78 (1985) 719-722.

[30] R.M. Barrer, I.S. Kerr, 66. Hydrothermal chemistry of the silicates. Part XI. Habit and surface topography in synthetic crystals of the analcite group, Journal of the Chemical Society (Resumed), (1963) 434-440.

[31] J.A. Gard, R.M. Barrer, J. Baynham, The hydrothermal chemistry of silicates. Part VI. A lamellar habit in synthetic felspar, Journal of the Chemical Society (Resumed), (1955) 24802481.

[32] C. Liu, W. Gu, D. Kong, H. Guo, The significant effects of the alkali-metal cations on ZSM-5 zeolite synthesis: From mechanism to morphology, Microporous and Mesoporous Materials, 183 (2014) 30-36.

[33] D. Zhao, R. Szostak, L. Kevan, Role of alkali-metal cations and seeds in the synthesis of silica-rich heulandite-type zeolites, Journal of Materials Chemistry, 8 (1998) 233-239.

[34] R. Aiello, F. Crea, E. Nigro, F. Testa, R. Mostowicz, A. Fonseca, J.B. Nagy, The influence of alkali cations on the synthesis of ZSM-5 in fluoride medium, Microporous and Mesoporous Materials, 28 (1999) 241-259.

[35] G. Majano, A. Darwiche, S. Mintova, V. Valtchev, Seed-Induced Crystallization of Nanosized Na-ZSM-5 Crystals, Industrial \& Engineering Chemistry Research, 48 (2009) 7084-7091.

[36] S. Mintova, N.H. Olson, J. Senker, T. Bein, Mechanism of the Transformation of Silica Precursor Solutions into Si-MFI Zeolite, Angewandte Chemie International Edition, 41 (2002) 2558-2561.

[37] B.J. Schoeman, The homogeneous nature of clear TPA-silicalite-1 precursor solutions, Microporous Materials, 9 (1997) 267-271.

[38] Z. Qin, L. Hafiz, Y. Shen, S.V. Daele, P. Boullay, V. Ruaux, S. Mintova, J.-P. Gilson, V. Valtchev, Defect-engineered zeolite porosity and accessibility, Journal of Materials Chemistry A, 8 (2020) 3621-3631.

[39] V. Valtchev, G. Majano, S. Mintova, J. Pérez-Ramírez, Tailored crystalline microporous materials by post-synthesis modification, Chemical Society Reviews, 42 (2013) 263-290.

[40] S.H. Park, R.W. Große Kunstleve, H. Graetsch, H. Gies, The thermal expansion of the zeolites MFI, AFI, DOH, DDR, and MTN in their calcined and as synthesized forms, in: H. Chon, S.-K. Ihm, Y.S. Uh (Eds.) Studies in Surface Science and Catalysis, Elsevier1997, pp. 1989-1994.

[41] C.A. Fyfe, J.H. O'Brien, H. Strobl, Ultra-high resolution 29Si MAS NMR spectra of highly siliceous zeolites, Nature, 326 (1987) 281-283.

[42] J.M. Chezeau, L. Delmotte, J.L. Guth, Z. Gabelica, Influence of synthesis conditions and postsynthesis treatments on the nature and quantity of structural defects in highly siliceous MFI zeolites: A high-resolution solid-state 29Si n.m.r. study, Zeolites, 11 (1991) 598-606. [43] E.M. Flanigen, J.M. Bennett, R.W. Grose, J.P. Cohen, R.L. Patton, R.M. Kirchner, J.V. Smith, Silicalite, a new hydrophobic crystalline silica molecular sieve, Nature, 271 (1978) 512-516.

[44] H. Van Koningsveld, High - temperature (350 K) orthorhombic framework structure of zeolite H - ZSM - 5, Acta Crystallographica Section B: Structural Science, Crystal Engineering and Materials, 46 (1990) 731-735. 
[45] C.A. Fyfe, D.H. Brouwer, A.R. Lewis, J.-M. Chézeau, Location of the Fluoride Ion in Tetrapropylammonium Fluoride Silicalite-1 Determined by 1H/19F/29Si Triple Resonance CP, REDOR, and TEDOR NMR Experiments, Journal of the American Chemical Society, 123 (2001) 6882-6891.

[46] E. Dib, T. Mineva, P. Gaveau, B. Alonso, 14N solid-state NMR: a sensitive probe of the local order in zeolites, Physical Chemistry Chemical Physics, 15 (2013) 18349-18352.

[47] S. Bordiga, P. Ugliengo, A. Damin, C. Lamberti, G. Spoto, A. Zecchina, G. Spanò, R. Buzzoni, L. Dalloro, F. Rivetti, Hydroxyls nests in defective silicalites and strained structures derived upon dehydroxylation: vibrational properties and theoretical modelling, Topics in Catalysis, 15 (2001) 43-52.

[48] K. Yamagishi, S. Namba, T. Yashima, Defect sites in highly siliceous HZSM-5 zeolites: a study performed by alumination and IR spectroscopy, The Journal of Physical Chemistry, 95 (1991) 872-877. 